\title{
Cogenerating insights into the dialectics of contemplative practices in educational and lifeworld settings
}

\author{
Grant Zouch $^{1} \cdot$ Joanna Higgins ${ }^{1} \cdot$ Suskya Goodall ${ }^{1} \cdot$ Robyn Browne $^{1}$
}

Received: 14 January 2021 / Accepted: 21 January 2021 / Published online: 3 September 2021

(c) The Author(s), under exclusive licence to Springer Nature B.V. 2021

\begin{abstract}
Contemplative practices are used with increasing frequency across various fields of knowledge, and increasingly so within educational settings as a means of promoting wellness and wellbeing. In this paper, we draw on qualitative data derived from primary students' experiences of meditative breathing and use them as a springboard to extrapolate meaning and cogenerate novel insights around contemplative practices. Theoretically framed within an authentic inquiry I contemplative inquiry dialectic, this approach seeks to situate the research team within the contemplative process, striving to make a difference for stakeholders. Intentionally acknowledging and drawing on our values, beliefs, and lifeworlds, this authentic inquiry I contemplative inquiry allows for the cogeneration of deep and meaningful insights. Insights coalesce around four emergent dialectics of contemplative practices: relaxed I stressed, attentive I distracted, still I energized and unbounded I constrained. Our co-constructed contemplative narrative argues that within the complex space of unbounded
\end{abstract}

Lead Editor: K. Tobin.

This manuscript is part of the special issue Contemplative Inquiry, Wellbeing and Science Education, guest edited by Kenneth Tobin.

Joanna Higgins

joanna.higgins@vuw.ac.nz

Grant Zouch

grant.zouch@vuw.ac.nz

Suskya Goodall

suskya@gmail.com

Robyn Browne

rob.browne@xtra.co.nz

1 Victoria University of Wellington, 15A Waiteata Road, PO Box 600, Wellington 6140,

New Zealand 
fields, contemplative practices have the potential to transform physical, mental, emotional, and social lifeworlds through a contagious individual and collective ripple effect.

\begin{abstract}
Contemplatieve praktijken worden steeds vaker toegepast op verschillende kennisgebieden, en in toenemende mate binnen educatieve instellingen als middel om gezondheid en welzijn te bevorderen. In dit artikel gebruiken we kwalitatieve data afkomstig van de ervaringen van basisschoolleerlingen met meditatieve ademhaling als springplank om betekenis te extrapoleren en nieuwe inzichten rond contemplatieve praktijken te genereren. Theoretisch afgebakend binnen een authentiek onderzoek I contemplatieve onderzoeksdialectiek, tracht deze benadering het onderzoeksteam binnen het contemplatieve proces te plaatsen met het streven een belang te maken voor belanghebbenden. Authentiek onderzoek I contemplatief onderzoek maakt het mogelijk om door onze waarden, overtuigingen, en leefwerelden bewust te erkennen, diepe en betekenisvolle inzichten te genereren. Onze inzichten komen samen rond vier opkomende dialectische stromingen van contemplatieve praktijken: ontspannen I gestresst, aandachtig I afgeleid, kalm I energiek en onbeperkt I beperkt. Op basis van ons gezamenlijk geconstrueerde contemplatieve verhaal stellen we dat contemplatieve praktijken het potentieel hebben om binnen de complexe ruimte van onbegrensde velden fysieke, mentale, emotionele en sociale leefwerelden te transformeren via een besmettelijk individu en een collectief rimpel effect.
\end{abstract}

Keywords Authentic inquiry · Contemplative inquiry · Contemplative practice · Mindfulness · Wellbeing · Contemplatieve praktijken · Authentiek onderzoek · Contemplatief onderzoek $\cdot$ Welzijn $\cdot$ Opmerkzaamheid

\title{
Emergent contemplations
}

In the harmonious flow of life, there is transformative potential for incorporating contemplative practices, pedagogies, and inquiry. Recently Oren Ergas (2019) called for discourse on the encounter between contemplative and educational practices "to examine the place of contemplative practices in and/or as education" (p. 1493). Within this broad scope lie opportunities to enhance classroom life for learners and their teachers in primary schools. Classrooms are by nature dynamic generators of culture where a fusion of values and practices is ever-present. In contemplating the meaning and purpose of classrooms, we adopted a "dialectically entangled process" (Alexakos, 2015, p. 1) to contemplate our positioning as researchers and teachers in interpreting a meditative breathing intervention. We realized that to expand our roles to include contemplators was necessary and thus our multilectical role as teacher I researcher I contemplator emerged.

From systematic methods of formal exercises such as meditation through to mindful walking, contemplative practices are a burgeoning field within transformative education (Kasworm and Bowles, 2012). In our minds, we intentionally position the phrase "contemplative practices" as an umbrella term that includes mindfulness practices such as meditation. Reflecting on the scope of contemplative practices, Maia Duerr (2004) developed a metaphor she called "The Tree of Contemplative Practices." Her model is grounded by communion, connection, and awareness in the form of roots with branches as "groupings of practices" such as movement practices, stillness practices, creative practices, generative, activist, ritualistic, and relational practices. Narelle Lemon (2021, this issue) promoted contemplative 
pedagogy employing poetic representation in a study of pre-service teachers' self-care. We were struck by the current "contemplative revolution" (Zajonc, 2013) based on quieting the mind to increase individual capacity for self-awareness, attentiveness, openness, and connection. We considered Richard Cleveland's (2019) conceptualization of mindfulness as being "more than a mere state of mind, but conscious moment-by-moment awareness of emotional, cognitive, and physical experiences" (p. 1116). Noticing or observing each moment with openness and acceptance enables an unbounded sense of awareness (Higgins and Eden, 2018). Increasingly, mindfulness-based interventions are being applied to enhance student and teacher wellbeing from early childhood to adult education contexts (Higgins and Keane, 2018).

In this piece, we build on Kenneth Tobin's concept of "mindfulness as a way of life" (2016, p. 1) through a meditative breathing intervention within a New Zealand primary classroom. Drawing on Vipassana Buddhist practices, Wong and Faikhamta's (2021, this issue) account of mindfulness practices in Grades 4 and 5 remind us that "mindfulness produces a non-dualistic way of thinking that is vital for developing an education that is not a one-way didactic process but instead is dialogical." Our purpose in writing this article is to use students' experiences of meditative breathing dialogically as a springboard to extrapolate meaning and cogenerate novel insights around contemplative practices. At this point, we explain our contemplative process before delving into a dialectic analysis and tangential musings.

\section{Authentic inquiry | contemplative inquiry}

Uniting concepts that may seem paradoxical, we seek to illuminate salient insights through dialectic relationships. "The dialectic relationship cautions that constructs considered in this way are inseparable constituents of the whole in which all postulated components presuppose the existence of one another" (Tobin, 2018, p. 33). Usually indicated by a Sheffer stroke, dialectical relationships illustrate how each part informs and mediates the other to establish a whole. From the way, we extrapolate meaning to our analysis and discussion of implications, entangled dialectics serve to uncover nuanced meaning and insight. We intentionally highlight the contradictions in the students' turns of phrase as "seeds for transformation" (Tobin, 2018, p. 33). It is through these seeds that we seek to shed light on contemplative practices. Exploring new methodological directions, we clarify the authentic inquiry I contemplative inquiry dialectic by describing authentic inquiry and explaining contemplative inquiry before addressing the relationships between the two constructs.

Authentic inquiry is a research framework that situates researchers within the research. An essential principle of authentic inquiry is the exploration of what we do, how we do it, and why we do it (Tobin, 2018). Alexakos (2015) expanded:

Authentic inquiry is dynamic, dialectic, recursive, reflexive, and continuous. Authentic. inquiry infuses systematic, purposeful, empirical studies with an active commitment to. authenticity criteria and interventions to improve the lives of all stakeholders. Authentic. inquiry unites the essence of seeming opposites, like theory and practice, teaching and. doing research, and teaching and learning. (p. 41)

Our inquiry insights inspire commitment to making a difference in the lives of stakeholders, now and in the future. From a lifeworld perspective we, the authors, can draw from our own experiences as students in classrooms and as teachers of primary-aged students. Furthermore, all members of our research team have previously practiced mindful breathing 
with our students. The individual and collective lifeworld experiences we have had allow us to explore the relationship between data sets and researchers through an authentic lens.

According to Bhattacharya (2017), contemplative inquiry "is a set of practices that allow us to have first person understanding of our inner dynamics." Activating our values and beliefs and how we connect with our world, contemplative practice allows for deep, meaningful insights, especially when practiced with a group of people. Consequently, the degree of connection and vulnerability on the contemplative inquiry journey is noteworthy (Bhattacharya, 2017). Interestingly, Ergas (2019) argued that "contemplative pedagogies and contemplative inquiry may seem novel when incorporated in contemporary educational institutions" (p. 1497). Novel or not, contemplative practices are becoming more mainstream in educational settings.

We view the dialectical relationship between contemplative inquiry and authentic inquiry as an instinctive and creative complementary experience that allowed us to think tangentially while tethered to our focus on meditative breathing in educational settings. With authentic inquiry always uppermost in our minds, the tangential contemplations often included telling stories of previous life experiences and diverse research areas, thus developing a deep sense of connectedness and vulnerability. This practice created a thin coherence of shared values and beliefs about mindfulness and education from which we launched our wanderings and wonderings of collective experience.

\section{Teacher | researcher | contemplator}

Forging a different way of interacting with data and each other within the scope of authentic inquiry I contemplative inquiry, we view our role multilectically as teacher I researcher I contemplator. Gene Fellner (2014) noted that "multilectics ... [embraces] multiple perspectives, values contradictions as intrinsic to reality" (p. 172). Being a contemplator adds a nuanced dimension that allows for deviation from notions of research. Within the role of a contemplator, the norms of researching are disrupted, creating space for philosophical wanderings and wonderings. As contemplators, there were times when we stood back reflexively and observed ourselves as a teacher I researcher. The role of teacher I researcher I contemplator gave us space to be vulnerable and more philosophical in our approach, revealing and illuminating collective insights. Noble and Powietrzyńska's (2021, this issue) use of the notion of "space" mediated our emerging understanding of our contemplative writing process. The contemplative process of collaborative writing via Google-Zoom meetings was, we realized, in itself a cogenerative writing environment. Our dynamic, fluid, and organic process were strengthened by contemporaneous peer review within reflective reading pods.

Constrained by our current research circumstances due to the coronavirus pandemic, we chose to adjust our perception of data gathering. Intentionally disrupting the norm that we need new data each time we analyze, we favored the concept of sustainable research through the reuse of data gathered by a colleague. The students' turns of phrase led us to springboard ideas and generate momentum to extrapolate meaning. The process of intuitively co-constructing interpretations to cogenerate novel insights is indicative of a different relationship with the data and its dialectical analysis and discussion. 
To further develop authentic inquiry I contemplative inquiry, we considered how we might build commentary on the vignettes to arrive at a co-constructed contemplative narrative based on the students' turns of phrase. To reflect our teacher I researcher I contemplator multilectic, we built our narrative on the following rubric:

- What's salient?

- Why is this salient?

- How is this exemplified in the students' turns of phrase?

- How is this relevant to our lifeworlds?

\section{How the data were gathered}

Our contemplations on mindfulness practices were inspired by a meditative breathing intervention with nine- and ten-year-old students in a primary school in Aotearoa New Zealand. Browne (2020), the classroom-based researcher, explained that "data were collected from the weekly cogenerative dialog, journals, from a heuristic and teacher recorded reflections with a three-month follow-up" (p. iii). The intervention consisted of audio-guided meditative breathing sessions based on Snel's (2013) program Sitting Still Like a Frog. At the beginning of each day students participated in 10-min sessions with a new exercise each week. Body relaxation prompts engaged parts of the body prior to the breathing practice. The meditative practice was introduced through the metaphors of "tuning their instrument of learning" and "preparing their learning muscles for the day's learning" (Browne, 2020, p. 40). Cogenerative dialoguing (cogen) (Roth and Tobin, 2002) provided an opportunity for participants to reflect on their experiences of meditative breathing for that week. For 10 min following the cogen, students were invited to capture in words or drawings their ideas around the practice. Each week students had an opportunity to journal around their meditative breathing experiences. Three months after the 10-week program of meditative breathing further data were gathered through cogens. For this paper, we draw exclusively on data from the cogens.

\section{Dialectical insights}

relaxed I stressed

"Your mind is your own world"

Talia: I think meditating to me is leaving all of the worries and just being yourself and having fun.

Denise: Meditating breathing is relaxing and it's flushing away all of the bad memories and the bad things that you have done in the past.

Olive: It takes away my worries and lets me focus on the good things in my life. I'm able to let go of all my anxieties. 
Richard: I find meditation really useful when I'm pressured. For example, when I was doing a quiz and we used it quite a bit and it helped us become more confident. We did it before we were going to speak and I really appreciate it. It is a great skill.

Kiri: I think I speak for everyone when I say your mind is your own world and stress and pressure is just locked outside and never coming back and you can do whatever you want and just not think of bad things.

When exploring the relationship between stress and relaxation, we realized that meditative breathing can be a powerful tool for students to reframe their experiences and make decisions. Disrupting the notion of simply reacting, turns of phrase alluded to an ability to choose a response. Shapiro et al. (2006) identified three aspects of mindfulness: attitude, attention, and intention. Students expressed their attitude or feelings in that moment, whether it was worried, anxious, pressured, or stressed. For example, a student explained, "I'm able to let go of all my anxieties." Undoubtedly some students had happy thoughts, however, we note that within the turns of phrase some students identified negative emotions prior to the meditative breathing. In turning to the notion of attention, some students redirected their thoughts and focus toward more positive aspirations such as meditative breathing "lets me focus on the good things in my life." In terms of intention, turns of phrase like "just being yourself and having fun" and "you can do whatever you want" infers a degree of freedom or open-endedness in their potential thoughts and actions.

Additionally, we noticed the dialectic of relaxed I stressed was underpinned by a sense of autonomy over their state of mind. Meditative breathing allowed students to focus on "flushing away," "letting go," "relaxing," "being yourself," and "having fun." We wondered if this autonomy was at the heart of meditative breathing in a classroom setting. A concept used by Covey et al. (1994) entered our contemplations: "Between stimulus and response there is a space. In that space lies our freedom and power to choose our response. In those choices lie our growth and our happiness" (p. 59). We regard the stimulus as comprising the lifeworld experiences of students with meditative breathing being a tool that expands the space between stimulus and response. Furthermore, we suggest that a response can be internal, like choosing a thought, or external, such as taking physical action. The freedom and power to reflect on possibilities and select responses were poignantly encapsulated by one student's sentiment that "your mind is your own world." Perhaps there is an indestructible seed deep within individuals that makes us who we are and within that seed lies the power to choose our attitude, attention, and intention regardless of our circumstances.

attentive I distracted

"Ready for the day"

Eli: In the morning I sometimes get distracted by noises and other things and then as you practice meditation you get better and it just calms you down more every time.

Tane: Meditation helps me as a learner because in the mornings if you meditate it just gets rid of everything that may have happened in the morning and it just lets you feel calm and lets you be able to focus on things a bit more easily.

Cail: For me meditation relaxes me and gets me all ready for the day.

Denise: I agree with Tane because in the mornings when you're really stressed and then you meditate and then you can carry on with the day and have a good day. 
Tane: If you have a really hard job, it's hard to focus on positive things cos you've been stressing a lot and you need to get up early and you don't really have enough time to just think about positive things and really focus.

When contemplating the attentive I distracted dialectic we thought about the transfer of focus required when transitioning between the social structures of the playground and classroom and how these settings generated an awareness of shifting from one space to another. The transition to learning preparedness can be individually challenging for both learners and teachers. We discussed the notion of students being distracted in terms of our own teaching practice. Interestingly, in our experiences, we differed in the timing of mindfulness-based breathing. However, we noted that each occurrence was at a transition point; either at the beginning of the day or after a break. So, why is this salient? Perhaps to "smooth the move" for students and teachers from potentially distracted frames of mind to more attentive ones. One student encapsulated this notion through the turn of phrase "gets me all ready for the day." We perceive meditative breathing as a tool that facilitates and supports transitions, rippling out to sustain learning states throughout the day.

In discussing Buddhist practices in education, Elizabeth Watts (2020) spoke about "the cultivation of undistracted attentiveness," (p. 134) which aligns with our attentive I distracted dialectic. Productive learning states are suggested by turns of phrase such as "it ... lets you be able to focus on things a bit more easily" and "really focus." Students' use of the term "focus" alludes to the attentiveness conducive to learning. Uppermost in our minds was the development of focused concentration in our "way of being in the world" to support learning states. In thinking about what focused concentration might look like, we noticed an apparent contradiction between being attentive (on task) and distracted (off task). The flux and flow of "being in the present moment" can simultaneously be seen as distracted and attentive to different objects of focus. However, whether a student is on or off task is a subjective judgment made by the observer. For instance, a student engaged in following the path of an ant may appear to some as being highly distracted and to others as being highly attentive. In today's world, the capacity to be attentive is offset by the explosive potential for individual and collective distraction. In this sense, we envisage the classroom as a microcosm of lifeworlds bursting with possibilities for students and their families.

still I energized

"It makes my brain feel like sunshine"

Eli: After doing the run it [mindful breathing] flushes away the tired puffer [puffed] feeling.

Tane: It's very calming, it's helpful giving me energy after each run.

Kiri: Meditation calms your body.

Eli: It makes me feel energized.

Kiri: Meditation is peaceful, it gives me energy to think.

Sione: I think meditative breathing makes me calm ... and it helps me to have energy and the energy helps me to think and learn.

Jodie: I think meditation breathing makes me calm and it helps me to go to bed and it helps me to have energy for the whole day and the energy helps me to learn and think. 
Denise: It helps me with my mood throughout the day, it makes my brain feel like sunshine.

Kiri: It makes me feel good, strong.

Richard: Healthy. It helps me to get on with my day.

Sione: It refreshes me.

Paora: During meditation today I felt like I had cool water crawling down my body and it felt so good and I love MB so much.

We puzzled over the components of the dialectic for this sequence-calm I energized or still I energized?-and what exactly the notion of energy refers to. Initially, we thought of physical states but soon realized that students may diverge in their meaning of energy when making comments like "it makes me feel energized." When students used the word "energy" or "energized" they appeared to be referring to a positive, happy state, which is apparent in their references to "sunshine." This prompted us to acknowledge different forms of physical and mental energy and to contemplate the forms and patterns of energy present in the classroom. We reflected on the ways in which teachers calm students after breaks, such as through silent reading, teacher reading, and drawing. The turn of phrase "the energy helps me to learn and think" suggested that the practice of meditative breathing energized students and helped them with their learning.

As we reflected further on the question of what it means to be "energized" we noted a connection between mood and sunshine. Turns of phrase like "it helps me with my mood throughout the day" and "it felt so good" appeared to reference positive emotional energy or feelings. Tane seemed to use meditative breathing as a replenishing tool, attributing it to "giving me energy." The notion of energy in the classroom setting and the different forms it can take is central to understanding the complexities of meditative breathing as a contemplative practice.

Next, we considered what it means to be "still." The turns of phrase "meditation is peaceful" and "meditation calms your body" brought us to the realization that our notions of stillness encapsulated being both calm and peaceful. We thought that this implied a combination of physical stillness and a mental calmness brought on by a slowing down of one's thoughts. In a secular classroom setting students are occasionally instructed to "be still" or "be quiet" in order to provide a safe learning environment, but not all of them necessarily have tools such as meditative breathing or meditative walking to support this directive. For some students, being physically still within the meditative breathing intervention required a significant amount of self-discipline. In respect to self-discipline, Watts (2020) noted that "according to Buddhist teachings, if we can find enough stillness, we will naturally come face to face with our own goodness and have an innate sense of goodwill that guides us" (p. 137). Stillness, then, interacts with dual notions of energy. While ostensibly the turn of phrase "it makes me feel energized" could be seen to contradict the statement "meditation calms your body," we do not see the acts of "being still" and "being energized" as mutually exclusive states since they occur simultaneously in different forms. In uniting these dialectic opposites, both stillness and energy exist in physical, emotional, and mental states. 
unbounded I constrained

"You're really free"

Eli: Meditation for me in the mornings gets me ready for the day and sometimes it can be quite stressful and then I'm doing meditation.

Olive: I like doing the meditation as it calms me. I even used it before surgery and was calm in seconds.

Richard: When I was doing a quiz, we used it quite a bit and it helped us become more confident and we did it before we were going to speak.

Tane: Sometimes you can feel like you're behind bars and you don't really have choices but if you meditate, pretty much you're not behind bars anymore and you're really free and can do whatever you want.

Charlie: When I meditate I usually think of like I can do anything. For example, I can fly, I can go underwater and I can breathe and I can just do anything.

Richard: I agree with everyone because they're all really good and meditating helps me as a learner to try to focus on the future and let the past go and it also helps me if I'm time pressured and makes me think of how I can do better things and help others. When I meditate I imagine that I'm a Buddha. It makes me feel like I'm in a temple in Thailand and I can just enjoy myself and it helps me develop new skills. It's quite a strong skill in itself.

Meditative breathing allows the participant to become aware (or more aware) of what is going on subconsciously, observing the stream of their thoughts from a somewhat detached position. Rather than a stream of consciousness, a stream of subconsciousness emerges. Moving between subconscious and conscious fields enables the possibility of deliberately choosing a response. Supporting the notion of being agentic, Tane expounded the idea that "sometimes you can feel like you're behind bars and you don't really have choices but if you meditate, pretty much you're not behind bars anymore and you're really free and can do whatever you want." Transitioning from a state of constraint to feeling free to act demonstrates the power of mindfulness to dissolve boundaries and move to an autonomous state of being.

As an addition to dissolving boundaries, meditative breathing influenced various areas of student life to span social fields of students' internal and external lifeworlds. As Higgins et al. (2016) reflected, "from a lifeworld perspective we became aware of the power of mindfulness breathing as a heuristic for connecting to other parts of life" (p. 69). We thought that this quote connected students' turns of phrase with their external lifeworlds. Sentiments such as getting ready in the morning, preparing for a quiz, and undergoing surgery all spanned unbounded fields wider than daily meditative breathing exercises. In comparison, imaginative turns of phrase like "I can just do anything," "I can fly," "I'm a Buddha," and "it makes me feel like I'm in a temple in Thailand" resonated with us as constituting internal lifeworld constructs. The possibilities generated through meditative breathing expanded students' internal and external lifeworlds to become unbounded from previous constraints. 


\section{Transcendent contemplations}

In thinking about the process of capturing our collective voice, we found that constructing nuanced claims can be a tricky undertaking. We tended to react-individually and collectively-to each other's "claimy" statements, prompting rich discussions of the notions and constructs at hand. Sometimes these robust, free-flowing conversations were resolved quickly, while at other times, we "bogged down" for a week or more on a particular notion. Our fixation on the term "energy" was one such example. As we explored this notion from students' insights of their experiences of meditative breathing, we moved on to consider different types of energy, in particular, the concept of the intensity of emotional energy (Davis and Bellocchi, 2019). In considering energy, we subscribe to a multilogical perspective "that employs all salient knowledge systems to benefit humankind" (Tobin, 2016, p. 22). Thinking about educational contexts, we were influenced by interpretations of the term "energy" emanating from different knowledge systems. For example, the Jin Shin Jyutsu knowledge system attends to the life essence or ch'i of universal energy flowing harmoniously through the body (see Tobin, 2016).

Even so, we still found ourselves in a conceptual quagmire. Eventually, we had a group epiphany when the idea of "harmony" was introduced, which led us to revisit Tobin's work. In a chapter entitled "Mindfulness as a way of life," Tobin (2016) invites his readers to contribute their thoughts about his phrase "Be for what purpose?" We resonated with his suggestion and mused that one answer may be "to maintain harmony," which aligns with the often-cited teaching mantra "order before learning" (Doyle, 1983). We debated this notion and finally arrived at the point of thinking of harmony as a structure. This prompted us to return to Browne's metaphors of "tuning their instrument of learning" and "preparing their learning muscles for the day's learning," (Browne, 2020) which she described as her purpose for practicing meditative breathing with her class. To unpack "preparing for learning" we drew on Tobin's (2016) notions of "receptivity to learn" and being "positively valenced." Our discussion then raised a potential disconnect between the concepts of "calm" and "energy." In our opinion, the word "harmony" seemed to better align with the ever-present energy forces in a school setting than did the word "calm." A calm school perhaps conjures up a vision of Buddhist monks walking quietly through cloisters, hands clasped behind their backs, whereas a schoolyard of active children can still be harmonious at its core.

For us, the practice of meditative breathing can serve to foster harmony in the mind of the student by dissolving the boundary between the subconscious and conscious mind. By this we mean allowing students to become aware of any unsettling and/or disruptive thoughts and emotions they may be harboring so that they can let them go and refocus more on the "here and now" (Tobin, 2016). The harmony established through the practice of meditative breathing also has the potential to infect others and thus build a sense of classroom solidarity. Such a feeling of membership could conceivably be transferred to the wider school context, thereby creating a more harmonious "vibe" in the school generally. Using the idea that meditative breathing can change ways of being in the world, we suggest that the intervention "had the potential to catalyze changes in conduct-not just in the classroom but also in social life generally" (Tobin, 2018, p. 41). We were also reminded of Prime Minister Jacinda Ardern's refrain to "be kind" during Aotearoa New Zealand's response to the COVID-19 pandemic, a sentiment which has since rippled across that nation's society. 
Meditative breathing has the potential to transform both individual and collective experiences in educational settings and beyond. Ergas (2015) praises the "deep teachings" of mindfulness to bring about a "contemplative turn" within an individual I collective transformative agenda in education. Alternatively, the mandating of mindfulness interventions in schools and classrooms risks invoking an instrumentalist framing that contradicts the essence of practices promoting wellbeing. We see this as positioning mindfulness as a universal "one-size-fits-all" solution to fundamental issues in schooling. In our collective experience, not all students enjoy and/or fully engage with mindfulness practices in the classroom. Therefore, meditative breathing is not necessarily a silver bullet for transforming education, but rather a tool for supporting stakeholders to be present.

We assume that most people reading this paper will accept the idea of the "moment in time" being a foundation block of mindfulness: To master it represents the state of being mindful, of being "in the moment" or "in the now." But what does it mean to be "in the moment?" To be "in the now?" And what does Tane mean when he complained of not having "enough time to just think about positive things?" These questions prompted us to consider more deeply the words "moment" and "now" and "time." We entertained the possibility of there being a relationship between time in general and mindful breathing, which led us to agree that the "moment in time" warranted further contemplation on our part. Tobin (2016) asserts that "being present in the moment, or being aware of the moment, is central to the construct of mindfulness. A mindful person would not be looking forward or backward to time" (p. 4). However, by accepting the fact that time is related to mindful breathing by way of the present moment, an interesting contradiction is raised in which time; that is, the amalgamation of past, present, and future-is essentially unbounded, whereas the act of paying single-minded attention to "the now" is in itself an act born of constraint. And so the much-heralded "moment in time"- the Holy Grail of many mindfulness practices - finds itself wedged firmly between the past and the future. That said, some of Browne's students' turns of phrase such as "you're really free and can do whatever you want" and "I can just do anything" seemed to point to the other end of the unbounded I constrained dialectic.

We argue that mindful breathing is unbounded as the practitioner is free to choose any passing thought and release it at will. Wayne Dyer (2012) offers a mechanical metaphor to capture the process of how humans think:

You choose the thought that you prefer, from the trillions of thoughts that continuously flow through your mind on that never-ending conveyor belt. You can pick one that suits you, put it back, and take another at any time. (p. 83)

And note the last three words, "at any time." Julian Barbour (2000), a British physicist who has authored several books on the subject of time, describes everything-including our individual lifeworlds - as a "series of nows," which aligns with Dyer's conceptualization of the thinking process. We propose that imagination is contingent on the inextricable relationship between freedom of thought and time. Philosophers and psychologists have long associated the imagination with the mind, but where do original thoughts, those creative building blocks of the imagination, reside? While we do not claim to know the answer, surely it is not in the head/brain as that would imply boundaries and it is counterintuitive to think of the imagination as having boundaries. We also suggest that the difference between everyday thinking — often done on automatic pilot or subconsciously—and "being in the moment" is the time and attention committed to the mindful act, and the resultant increased awareness of thought that stems from being mindful. In debating the idea that being aware involves deliberately taking the time to be attentive, we agreed that the 
conscious fostering of awareness can lead to an enriched "understanding of one's experiences and reality" (Zhao et al. 2020, p. 163).

In our view, mindful breathing is a contemplative practice that is at the same time unbounded and constrained. It occurred to us that thought, imagination, and time share a common trait, that is, they "flow." Indeed, the idea that all three are dynamic, free-flowing, and in a constant state of flux proved important to the act of drawing thin coherences of meaning from a limited set of qualitative data. Ultimately it brought us back to the still I energized dialectic. Seeing dialectics all around us, we realized the transformative power of dialectical and multilectical relationships.

The first question we used to explore the still I energized dialectic was, what does it mean to be still? The adage "still waters run deep" resonated with us on many levels, not least of all because it implies that stillness and flow are not mutually exclusive terms. We also noted the fundamental aim of some mindfulness practices to "still the mind" and that the program Browne used in her intervention is called Sitting Still Like a Frog. In the process of contemplating what it means to be still, it became clear to us that time was once again a salient factor. Time has a symbiotic relationship with flow; flow is a measurable motion often observable in movement. It stands to reason that without flow there is no motion; no movement whatsoever: stillness. Moreover, without flow, there can be no time: timelessness. Admittedly, the whole concept of timelessness was too big for us to fully comprehend, but we still dared to ask ourselves, what is time?

Time (as opposed to timelessness) is something we all experience on a daily basisalbeit from a decidedly linear perspective - and therefore all humans have a personal understanding of it. Which is not to say time is an easy concept to "get your head around," as noted by Davis and Bellocchi (2018). It is a worthwhile undertaking to unpack "time" in the same way we unpacked "moment in time" above because both serve to inform our contemplations into the nature of mindfulness and meditative breathing. Earlier, one of Tane's turns of phrase caused us to wonder what time might mean to him. The fact that he lamented not having "enough" time implies that on some level he saw time in terms of a resource; something with measurable value to be managed and traded. We found it useful to think of time as a complex, human construct based on the laws of physics that is dependent on the flow and motion of the physical universe, from the sub-atomic to the cosmic.

The creation stories of many civilizations and religions describe a time of nothingness in the cosmos. The indigenous Māori of Aotearoa New Zealand speak of Te Kore, The Void, the realm of potential being. Genesis, the first book of the Hebrew Bible, invokes an earth "without form, and void [where] darkness was upon the face of the deep" (King James Bible, 2017, Genesis 1:2). Taoist doctrine is slightly different in that it portrays the primordial period as a time of chaos, which is not quite the same as nothingness. What unites these three creation stories, however, is the enigmatic concept of "formlessness" and the inherent potential existing within this state of (non)being. Science tells us that an initiating event known as The Big Bang gave birth to the universe in which we live. In that moment some kind of "unformed potential" was released and flowed outwards into space, spreading as it went not only matter but also an infinite field of possibilities. Somewhere in space and time a galaxy formed, and a brand new sun appeared around which our solar system manifested that included our planet. We chose to include this narrative on how the universe was created because it helps to explain where the construct of time originated. Moreover, the story shows how time relates conceptually to other significant components of mindfulness such as flow, matter, and energy. To summarize, we suggest the creative force present in the known universe finds expression through the movement (motion/kinetic energy) of matter (a form of energy) as it expands (flows) from 
nothingness into somethingness. But while all this may help us to contemplate the question of time from a cosmic standpoint, it only partially answers the question, what is time?

Through the very act of measuring time, humans are in effect imposing structure on it; constraining it - and themselves. Earlier we discussed the unbounded I constrained dialectic in relation to the human mind, focusing on the potential for mindful practitioners to dissolve the boundaries between the conscious and the subconscious. That memory prompted us to wonder if time too can be thought of dialectically in terms of unboundedness and constraint. Above we suggested that time - the amalgamation of past, present, and futureis essentially unbounded. Perhaps the most obvious time constraint for our intervention with students is the 9:00 a.m.-3:00 p.m. school day. Here, time serves to provide a linear framework for the class, school, and society as a whole to operate within. We contend that while "time unbounded" and "time constrained" are dialectically related in that both "postulated components presuppose the existence of one another," (Tobin, 2018, p. 33) a third equally important construct needs to be considered in this context. The "moment in time" (now/awareness) occupies a unique space equidistant from "time unbounded" and "time constrained," which can be conceptualized as the "still waters" beneath which the deep currents of chronological time (structure) and timelessness (chaos/no-thing-ness) run. In this regard, all three constructs share a multilectical relationship.

The cradle of chronological time lies literally in the stars, but the source of biological (body) time springs from more intuitive origins. Directed by electrical pulses from the brain, the rise and fall of the lungs are one way of tracking body time. Some meditative breathing practices aim to "investigate the nature of one's own experience," (Kwah, 2019, p. 1124) such as encouraging practitioners to focus on their breathing, to "count to six" on the inbreath and again on the outbreath as a way of settling into their own rhythm, as seen in the Sitting Still Like a Frog program (Snel, 2013). By being aware of their breathing, participants in mindfulness sessions subconsciously influence the flow of blood through their body. In breathing meditation, the breath is the resting place and thoughts are labeled as "wanderings," (Higgins et al., 2016) signaling a return to the present moment in order to bear witness to passing thoughts as an inevitable and harmonious human state of mind. Extending beyond thoughts, Tobin et al.'s study (2016) used polyvagal theory to investigate how meditative breathing can highlight physiological states associated with different types of emotional energy. In the spirit of non-judgmental scholarship (Cleveland, 2019), we seek to disturb the waters and create a "ripple effect" (Noble and Powietrzyńska, 2021, this issue) through our work by suggesting that for classrooms, it is also important to explore various forms of mindfulness from Buddhist traditions such as Theravada and Mahayana where, as Kwah (2020) pointed out, values of compassion and care are foundational.

Notwithstanding Tobin's (2016) interpretation of harmony which draws on alternative knowledge systems, we see harmony as representing a polyphonic synthesis of mindflow I bodyflow such as one might experience in a musical performance. Alongside the simple act of paying close attention to their breathing, Browne's purpose for her meditative breathing intervention was to help her students "tune their learning instrument" in order to create an individual sense of harmony. Sowing the seeds of transformation, we acknowledge the polysemic and holistic nature of individual harmony as being harmonious with physical, emotional, mental, social, and spiritual aspects of oneself. In the same way, a stone thrown into still waters causes a ripple effect, mindful breathing is simultaneously an individual and collective practice. Harmony has the potential to ripple out from the "tuned-in" individual to the classroom, playground, school, and community. Such solidarity among contemplative individuals is a form of symbolic capital (Tobin, 2012). Whenever a collective cacophony of individuals is in harmonious concert with one another, contemplative 
practices have the potential to transform physical, mental, emotional, social, and spiritual lifeworlds through a contagious individual and collective ripple effect.

Acknowledgements We would like to thank our colleagues Malgorzata Powietrzyńska, Linda Noble, and Narelle Lemon for their generosity of spirit in critiquing our work. We appreciated the ensuing rich discussions and the opportunities to deepen our understanding of theoretical constructs. We are also grateful to Jasper Hidding for preparing a Dutch language version of the abstract for this paper.

\section{References}

Alexakos, K. (2015). Being a teacher | researcher: A primer on doing authentic inquiry research on teaching and learning. Sense Publishers. https://doi.org/10.1007/978-94-6300-295-0

Barbour, J. (2000). The end of time: The next revolution in physics. Oxford University Press.

Bhattacharya, K. (2017). Kakali Bhattacharya defines contemplative inquiry [Streaming video]. SAGE Research Methods. https://doi.org/10.4135/9781473964433

Browne, R. (2020). Meditative breathing: a catalyst for positive change. Unpublished Master's thesis. Victoria University of Wellington.

Cleveland, R. (2019). Extending Tobin's mindfulness in education. Cultural Studies of Science Education, 14, 1115-1121. https://doi.org/10.1007/s11422-018-9899-4

Covey, S., Merrill, A. R., \& Merrill, R. R. (1994). First things first: to live, to love, to learn, to leave a legacy. Simon \& Schuster.

Davis, B., \& Bellocchi, A. (2018). Objectivity, subjectivity, and emotion in school science inquiry. Journal of Research Science in Teaching, 55, 1419-1447. https://doi.org/10.1002/tea.21461

Davis, B., \& Bellocchi, A. (2019). Intensity of emotional energy in situated cultural practices of science education. Cultural Studies of Science Education, 15, 359-388. https://doi.org/10.1007/ s11422-019-09931-0

Doyle, W. (1983). Academic work. Review of Educational Research, 53, 159-199.

Duerr, M. (2004). A powerful silence: the role of meditation and other contemplative practices in American life and work. A Report on the Contemplative Net Project The Center for Contemplative Mind in Society. http://www.contemplativemind.org/admin/wp-content/uploads/2012/09/APS.pdf

Dyer, W. (2012). Wishes fulfilled: Mastering the art of manifesting. Hay House.

Ergas, O. (2015). The deeper teachings of mindfulness-based 'interventions' as a reconstruction of 'education.' Journal of Philosophy of Education. https://doi.org/10.1111/1467-9752.12137

Ergas, O. (2019). Education and mindfulness practice: Exploring a dialog between two traditions. Mindfulness, 10, 1489-1501. https://doi.org/10.1007/s12671-019-01130-w

Fellner, G. (2014). Broadening of lenses of perception to advance learning: an introduction to multilectics. Teaching and Teacher Education, 37, 169-182. https://doi.org/10.1016/j.tate.2013.04.015

Higgins, J., Eden, R., \& Moeed, A. (2016). Mindfulness interventions in classroom learning environments. In M. Powietrzyńska \& K. Tobin (Eds.), Mindfulness and educating citizens for everyday life (pp. 59-72). Rotterdam: Sense Publishers.

Higgins, J., \& Eden, R. (2018). Emerging understandings of mindfulness through experiential awareness. Learning: Research and Practice, 4(1), 102-111. https://doi.org/10.1080/23735082.2018.1428144

Higgins, J., \& Keane, R. J. (2018). Mindfulness, learning and education. Oxford Bibliographies Online. https://doi.org/10.1093/OBO/9780199756810-0199

Kasworm, C., \& Bowles, T. (2012). Fostering transformative learning in higher education settings. In E. Taylor \& P. Cranton (Eds.), The handbook of transformative learning (pp. 388-407). Sage.

King James Bible. (2017). King James Bible Online. https://www.kingjamesbibleonline.org/ (Original work published 1769).

Kwah, H. (2019). Buddhist and arts-based practices for addressing racial oppression: Building upon Cleveland and Tobin's mindfulness in education. Cultural Studies of Science Education, 14, 11231131. https://doi.org/10.1007/s11422-018-9898-5

Kwah, H. (2020). Bringing a dialogue between Buddhist multilogicality and evolutionary science into the science classroom. Cultural Studies of Science Education, 15, 143-155. https://doi.org/10.1007/ s11422-019-09930-1

Lemon, N. (2021). Wellbeing in initial teacher education: using poetic representation to examine pre-service teachers' understanding of their self-care needs. Cultural Studies of Science Education, 16. https://doi. org/10.1007/s11422-021-10034-y 
Noble, L., \& Powietrzyńska, M. (2021). Holding space for uncertainty and vulnerability: reclaiming humanity in teacher education through contemplative I equity pedagogy. Cultural Studies of Science Education, 16. https://doi.org/10.1007/s11422-021-10035-x

Powietrzyńska, M., \& Tobin, K. (2014). Mindfulness and science education. In R. Gunstone (Ed.), Encyclopedia of science education. Springer.

Roth, W.-M., \& Tobin, K. (2002). At the elbow of another: learning to teach by coteaching. Peter Lang.

Shapiro, S. L., Carlson, L. E., Astin, J. A., \& Freedman, B. (2006). Mechanisms of mindfulness. Journal of Clinical Psychology, 62, 373-386.

Snel, E. (2013). Sitting still like a frog. Shambhala.

Tobin, K. (2012). Sociocultural perspectives on science education. In B. Fraser, K. Tobin, \& C. McRobbie (Eds.), Second international handbook of science education. Springer.

Tobin, K. (2016). Mindfulness as a way of life. In M. Powietrzyńska \& K. Tobin (Eds.), Mindfulness and educating citizens for everyday life (pp. 1-24). Sense Publishers.

Tobin, K., King, D., Henderson, S., Bellocchi, A., \& Ritchie, S. (2016). Expressions of emotions and physiological changes during teaching. Cultural Studies of Science Education, 11, 669-692. https:// doi.org/10.1007/s11422-016-9778-9

Tobin, K. (2018). Methodological bricolage. In S. Ritchie \& K. Tobin (Eds.), Eventful learning: Learner emotions (pp. 31-55). Brill Sense Publishing.

Watts, E. (2020). In search of a better means of increasing student receptivity to science: A look at American Buddhists and their disproportionately high acceptance of the theory of evolution. Cultural Studies of Science Education, 15, 121-141. https://doi.org/10.1007/s11422-018-9895-8

Wong, Y. Y., \& Faikhamta, C. (2021). Reconnecting self, others and nature. Cultural Studies of Science Education, 16. https://doi.org/10.1007/s11422-021-10033-z

Zajonc, A. (2013). Contemplative pedagogy: A quiet revolution in higher education. New Directions for Teaching and Learning, 134, 83-94. https://doi.org/10.1002/t1.20057

Zhao, S., Chang, D., Miyakawa, M., \& Bai, H. (2020). Critical care of creationism. Cultural Studies of Science Education, 15, 157-168. https://doi.org/10.1007/s11422-019-09928-9

Publisher's Note Springer Nature remains neutral with regard to jurisdictional claims in published maps and institutional affiliations.

Grant Zouch is a PhD candidate at Victoria University of Wellington. He was a primary teacher for fifteen years before a stress-related heart attack prompted a move into educational research. While Grant's wider research is centered on wellbeing, his doctoral thesis is a narrative inquiry into teacher attrition. It explores the personal narratives of former primary school teachers and how their experiences contributed to their decision to leave the classroom.

Joanna Higgins is an associate professor at the Faculty of Education, Victoria University of Wellington, New Zealand where she teaches in initial teacher education, masters and doctoral programs. She supervises masters and doctoral projects that focus on policy implementation, professional learning and development, leadership and wellbeing initiatives in schools and universities. Her research focuses on learning environments and policy implementation. Her work from sociocultural perspectives includes instructional reform in mathematics education, professional inquiry of teachers and teacher educators, and analyses of wellbeing policy and practice.

Suskya Goodall is a doctoral candidate at the Faculty of Education, Victoria University of Wellington with a research focus on actively enhancing wellbeing in centers, kura and schools of Aotearoa New Zealand. She is involved with initial teacher education, research fellow work, various committees and leads a project for doctoral students. Her work with schools, clusters, Ministry of Education projects centers around her passion for wellbeing at individual, organizational and sector-wide levels with theoretical influences of strengths-based and authentic leadership, ecological systems, appreciative inquiry and positive psychology.

Robyn Browne Robyn Browne is an advanced classroom expert teacher (ACET) of four decades experience. She is currently teaching years five and six students in a primary school in Aotearoa, New Zealand. Her passion and focus is on enabling students, families and teachers whose communities exhibit high levels of deprivation. Her evolving, lifelong meditative practice informs her educative practice. She recently completed her Master's thesis titled 'Meditative Breathing_A Catalyst for Positive Change.' 